\title{
Multiloop and Prediction Based Controller Design for Sugarcane Crushing Mill Process
}

\author{
Sandeep Kumar Sunori*, Pradeep Kumar Juneja**, Anamika Bhatia Jain*** \\ * Department of Electronics and Communication Engineering, Graphic Era Hill University, India \\ ** School of Electronics, GEU, Dehradun, India \\ *** Department of Electronics and Communication, GEU, Dehradun, India
}

\begin{tabular}{l} 
Article Info \\
\hline Article history: \\
Received Sep 22, 2015 \\
Revised Nov 4, 2015 \\
Accepted Nov 16, 2015 \\
\hline Keyword: \\
Decoupling \\
Model predictive control \\
Multivariable process \\
Relative gain array \\
Sugar mill
\end{tabular}

\begin{abstract}
In the present work a sugarcane crushing mill is presented as a MIMO system with high multivariable interaction.A linear model of the plant is taken with flap position and turbine speed as manipulated variables and mill torque and buffer chute height as controlled variables. The multiloop PI controller has been designed for this plant by first investigating the RGA and the value of Niederlinski index of this plant.The decoupling of this system is done and the respective open loop and closed loop step responses are observed and compared with those of the composite MIMO system. Also the performance of multiloop controller is compared with controller designed using model predictive control system strategy for this plant.
\end{abstract}

Copyright $@ 2015$ Institute of Advanced Engineering and Science. All rights reserved.

\section{Corresponding Author:}

Sandeep Kumar Sunori,

Departement of Electronics and Communication Engineering,

Graphic Era Hill University.

Bhimtal Campus, India.

Email: sandeepsunori@gmail.com

\section{INTRODUCTION}

The block diagram of sugarcane crushing mill process which a key sub process of sugar industry is shown in Figure 1.

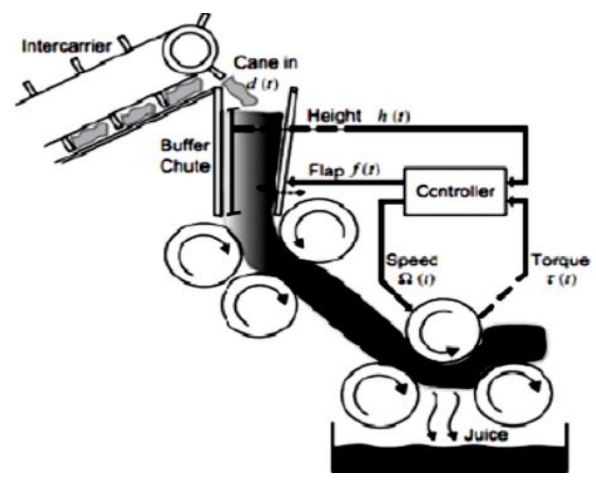

Figure 1. Crushing mill process [11] 
The control of two parameters namely buffer chute height $h(t)$ and mill toque $\tau(t)$ is very crucial for maximum juice extraction. The manipulated variables to control these parameters are the flap position $\mathrm{f}(\mathrm{t})$ and the turbine speed $\Omega(\mathrm{t})$.

Generally a train of 4 to 6 such mills in a sequence is employed in sugar industries. The feed which is in the form of shredded fibers contains the locked juice called bagasse is gravity fed into the chute. There is an arrangement of chute flap which can alter the aperture at the base of the chute. This way it controls the flow rate from the base. This material is then compressed by three groveed rollers and the primary juice is extracted. The waste bagasse is carried by the conveyer which is burnt to generate steam of high pressure required in steam turbines to produce electricity.

The model predictive controller (MPC) takes optimal control action on the basis of anticipation of future output samples for a predefined number of sampling intervals or control intervals [17]. The total time duration covered by these sampling intervals is called the prediction horizon.MPC technique has exhibited a remarkable performance in the field of industrial multivariable process control. The MPC predicts the output samples of the process for the predefined prediction horizon and formulates an objective function [18] using these samples. Now it obtains the optimum control moves in the manipulated variables for a predefind time duration called the control horizon such that the objective function is minimized.The control move is then sent to the plant. This cycle is repeated at every sampling instant. Thus an MPC works with the receding prediction and control horizons.

A fuzzy MPC technique was proposed for distillation column which is a complex nonlinear multivariable process [1]. The performance was reported to be better than that of conventional controllers. Michał Rogalewicz et al., used statistical methods to control manufacturing processes and compared univariate statistical process control (SPC) with multivariate SPC [2].

Multivariate statistical process control (MSPC) and Engg. Process control (EPC) were reported to be the two complementary techniques in the field of process control. EPC nullifies the impact of disturbance. SPC diagnoses the reasons of variations and removes them [3].

Particle swarm optimization (PSO) algorithm was used to design PID controller for a fuzzy model. PSO-PID controller was compared with Ziegler-Nicholes (ZN) PID controller. The reduction in the overshoot was reported in the former as compared to the latter [4]. P. Naidoo et al., set up communication between the control system and the process field devices using profibus-PA and profibus-DP. A PLC was used to control the plant [5].

A control strategy was developed to control a continuous polymerization reactor and its performance was evaluated using simulations [6]. Dan Altena et al., applied advanced multivariable control on a natural gas plant and its performance was compared with the conventional feedback controllers. This paper also focused on control strategy for complex turbo expander process [7].

Dynamic matrix control (DMC) scheme was used for a drum boiler turbine. An intelligence based decision mechanism (IBDM) was implemented which supported both model approach and control scheme [8]. R. Hanuma Naik et al., [9] developed decentralized controller for multivariable process based on RGA and Neiderlinski index analysis. An algorithm was developed by integration of multi resolution analysis (MRA) and principal curves (PC) for controlling multivariable processes [10].

\section{PLANT MODEL AND ITS MULTIVARIABLE ANALYSIS}

The transfer function model of the considered crushing milling plant is shown in Figure 2.

$$
\left[\begin{array}{l}
\tau \\
h
\end{array}\right]=\left[\begin{array}{cc}
\frac{-5}{25 s+1} & \frac{s^{2}-0.05 s-0.005}{0.1 s^{3}+1.1 s^{2}+s} \\
\frac{1}{25 s+1} & \frac{-0.0023}{s}
\end{array}\right]\left[\begin{array}{l}
f \\
\Omega
\end{array}\right]
$$

Figure 2. Transfer function of crushing mill [11]

Where the controlled variables $\tau(\mathrm{t})$ and $\mathrm{h}(\mathrm{t})$ are the mill torque and buffer chute height respectively and the manipulated variables $\mathrm{f}(\mathrm{t})$ and $\Omega(\mathrm{t})$ are flap position and turbine speed set point respectively. The open loop step response of this model is shown in Figure 3.

It shows that the pairings turbine speed-mill torque and turbine speed-buffer chute height exhibit an inverse response.This feature makes it difficult to achieve accurate, independent control of the two controlled variables. 


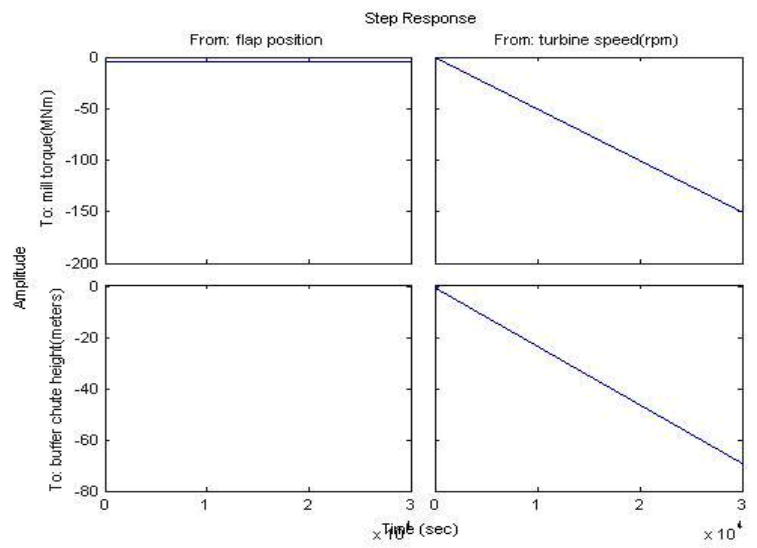

Figure 3. Open loop step response of crushing mill model

Before designing the multiloop controller for the considered plant the suitable pairing between manipulated and control variables is done by determining the relative gain array (RGA) [14]. Consider the steady state model of a 2x2 MIMO plant.

$$
\left[\begin{array}{l}
y_{1} \\
y_{2}
\end{array}\right]=\left[\begin{array}{ll}
K_{11} & K_{12} \\
K_{21} & K_{22}
\end{array}\right]\left[\begin{array}{l}
u_{1} \\
u_{2}
\end{array}\right]
$$

Where $\mathrm{u}_{1}, \mathrm{u}_{2}$ are manipulated variables and $\mathrm{y}_{1}, \mathrm{y}_{2}$ are controlled variables. The steady state gain matrix is given by:

$$
[K]=\left[\begin{array}{ll}
K_{11} & K_{12} \\
K_{21} & K_{22}
\end{array}\right]
$$

Now the RGA is expressed as:

$$
\mathrm{RGA}=\left[\begin{array}{ll}
\lambda_{11} & \lambda_{12} \\
\lambda_{21} & \lambda_{22}
\end{array}\right]
$$

Where $\lambda_{12}=\lambda_{21}=1-\lambda_{11}$ and $\lambda_{22}=\lambda_{11}$ and,

$$
\lambda_{11}=\frac{1}{1-\frac{K_{12} K_{21}}{K_{11} K_{22}}}
$$

If $\lambda_{12}<\lambda_{11}$ then suitable pairing is $\mathrm{u}_{1}-\mathrm{y}_{1}$ and $\mathrm{u}_{2}-\mathrm{y}_{2}$ else it is $\mathrm{u}_{1}-\mathrm{y}_{2}$ and $\mathrm{u}_{2}-\mathrm{y}_{1}$

Using Equation (1)-(4) lets find out RGA for the considered plant.For this plant the steady state gain matrix is given below:

$$
[K]=\lim _{I \rightarrow \infty}\left[\begin{array}{cc}
-5 & -0.005 I \\
1 & -0.0023 I
\end{array}\right]
$$

Using relations (3), (4) and (5), the RGA is determined as:

$$
R G A=\left[\begin{array}{ll}
0.69 & 0.31 \\
0.31 & 0.69
\end{array}\right]
$$

This RGA suggests that the suitable pairing is $\mathrm{u}_{1}-\mathrm{y}_{1}$ and $\mathrm{u}_{2}-\mathrm{y}_{2}$

The second parameter is the Niederlinski index [12] which determines the closed loop stability of the control system. It is calculated using the following relation

$$
N=\frac{\operatorname{Det}[K]}{K_{11} K_{22}}
$$

The MIMO system will be unstable for all possible values of controller parameters if $\mathrm{N}<0$ [12]. 
Now using Equation (7), the Neiderlinski index for this plant is determined as:

$$
N=\lim _{I \rightarrow \infty} \frac{\left|\begin{array}{cc}
-5 & -0.005 I \\
1 & -0.0023 I
\end{array}\right|}{5 \times 0.0023 I}=1.43
$$

Hence for this plant $\mathrm{N}>0$ which indicates that the system is closed loop stable.

\section{CONTROLLER DESIGN}

Now the multiloop controller for this plant will be designed using Mc Avoy procedure [15] for a 2x2 system. As per this method any of single loop tuning rules eg., Ziegler-Nicholes, Cohen-Coon, etc can be first used to obtain the initial $\mathrm{K}_{\mathrm{p}}$ and $\mathrm{K}_{\mathrm{i}}$ values of the two PI controllers for $\mathrm{u}_{1}-\mathrm{y}_{1}$ loop (assuming $\mathrm{u}_{2}=0$ ) and $\mathrm{u}_{2}-\mathrm{y}_{2}$ loop(assuming $\mathrm{u}_{1}=0$ ). Assume, after this tuning the value of $\mathrm{K}_{\mathrm{p}}$ comes out to be $\mathrm{K}_{\mathrm{p}}{ }^{*}$. Now the two PI controllers for the considered 2x2 MIMO system will be tuned using the following relation [16],

$$
K_{p}=\left\{\begin{array}{r}
K_{p}^{*}\left(\lambda-\sqrt{\left(\lambda^{2}-\lambda\right)}\right) ; \text { for } \lambda>1.0 \\
K_{p}^{*}\left|\lambda+\sqrt{\left(\lambda^{2}-\lambda\right)}\right| ; \text { for } \lambda<1.0
\end{array}\right.
$$

Here, $\lambda$ being the relative gain parameter which is $\lambda_{11}$ element of the RGA.

The response could be first improved by the continued adjustment on the tuning parameter. Now for the considered plant, the tuned values of $\mathrm{K}_{\mathrm{p}}$ and $\mathrm{Ki}$ for $\mathrm{u}_{1-} \mathrm{y}_{1} \operatorname{loop}(\mathrm{SISO} 1)$ and $\mathrm{u}_{2}-\mathrm{y}_{2}$ loop(SISO2) are found to be $\left(\mathrm{K}_{\mathrm{p} 1}{ }^{*}=-0.0946, \mathrm{~K}_{\mathrm{i} 1}=-0.0128\right)$ and $\left(\mathrm{K}_{\mathrm{p} 2}{ }^{*}=-376.5328, \mathrm{~K}_{\mathrm{i} 2}=-217.3913\right)$ respectively. The closed loop step response of SISO1 system is shown in Figure 4. The characterstics of this response are presented in Table 1.

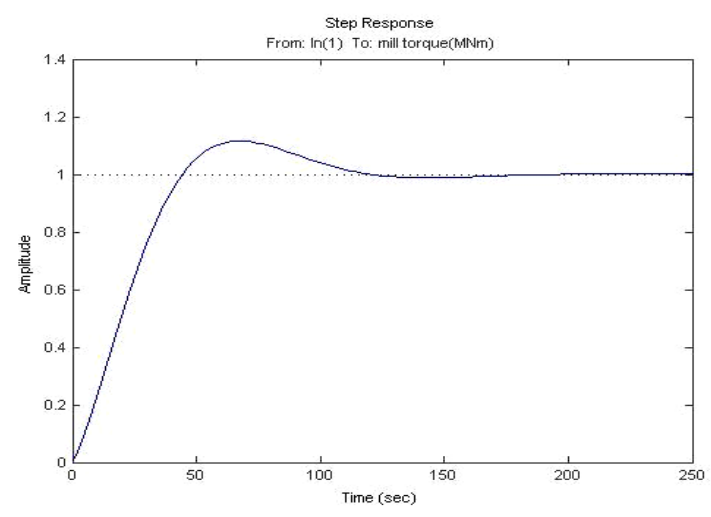

Figure 4. Closed loop step response of SISO1 system

Table 1. Closed loop step response characterstics of SISO1 system

\begin{tabular}{cc}
\hline Parameter & Value \\
\hline Rise time(sec) & 32.5 \\
Setteling time(sec) & 108 \\
Overshoot $(\%)$ & 11.6 \\
Peak amplitude & 1.12 \\
\hline
\end{tabular}

The closed loop step response of SISO2 system is shown in Figure 5. The characterstics of this response are presented in Table 2. 


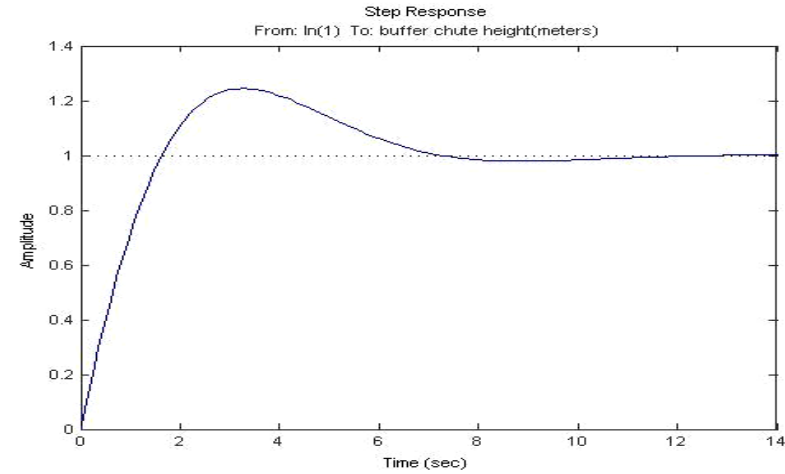

Figure 5. Closed loop step response of SISO2 system

Table 2.Closed loop step response characterstics of SISO 2 system

\begin{tabular}{cc}
\hline Parameter & Value \\
\hline Rise time $(\mathrm{sec})$ & 1.26 \\
Setteling time $(\mathrm{sec})$ & 9.43 \\
Overshoot $(\%)$ & 24.4 \\
Peak amplitude & 1.24 \\
\hline
\end{tabular}

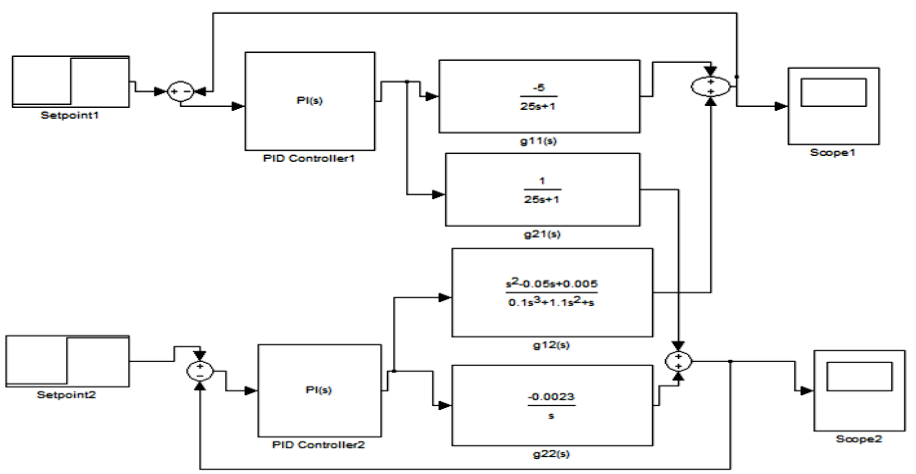

Figure 6. Simulink model of multiloop controller

With these initial values for PI controllers, the multiloop control system using Mc Avoy procedure is now modelled using MATLAB simulink, the corresponding simulink model is shown in Figure 6.

Now using the Mc Avoy rule of detuning given by Equation (9) only one time with the parameters presented in Table 3 only one time, the calculation leads to the value of $\mathrm{K}_{\mathrm{p} 1}=-0.0786$ and $\mathrm{K}_{\mathrm{p} 2}=-312.7520$ which gives rise to an unstable response hence it is not acceptable as shown in Figure 7.

Table 3. Parameters for Mc Avoy controller design

\begin{tabular}{cc}
\hline Parameter & Value \\
\hline$\lambda$ & 0.69 \\
$\mathrm{~K}_{\mathrm{p}} *$ & -0.0946 \\
$\mathrm{~K}_{\mathrm{i} 1}$ & -0.0128 \\
$\mathrm{~K}_{\mathrm{p} 2}{ }^{*}$ & -376.5328 \\
$\mathrm{~K}_{\mathrm{i} 2}$ & -217.3913 \\
\hline
\end{tabular}




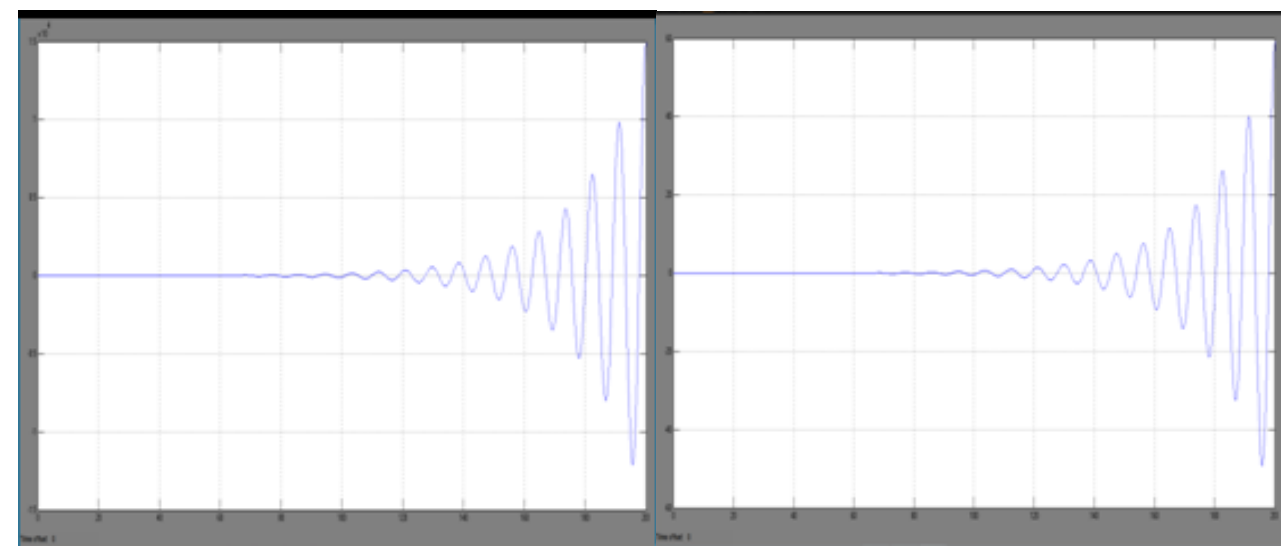

Figure 7. Responses of Mc Avoy controllers for mill torque (left) and buffer chute height (right)

Now doing the continued Mc Avoy adjustment five times the calculated value of $\mathrm{K}_{\mathrm{pl}}=-0.0374$ and $\mathrm{K}_{\mathrm{p} 2}=-148.854$. This results in an improved acceptable response as shown in Figure 8.

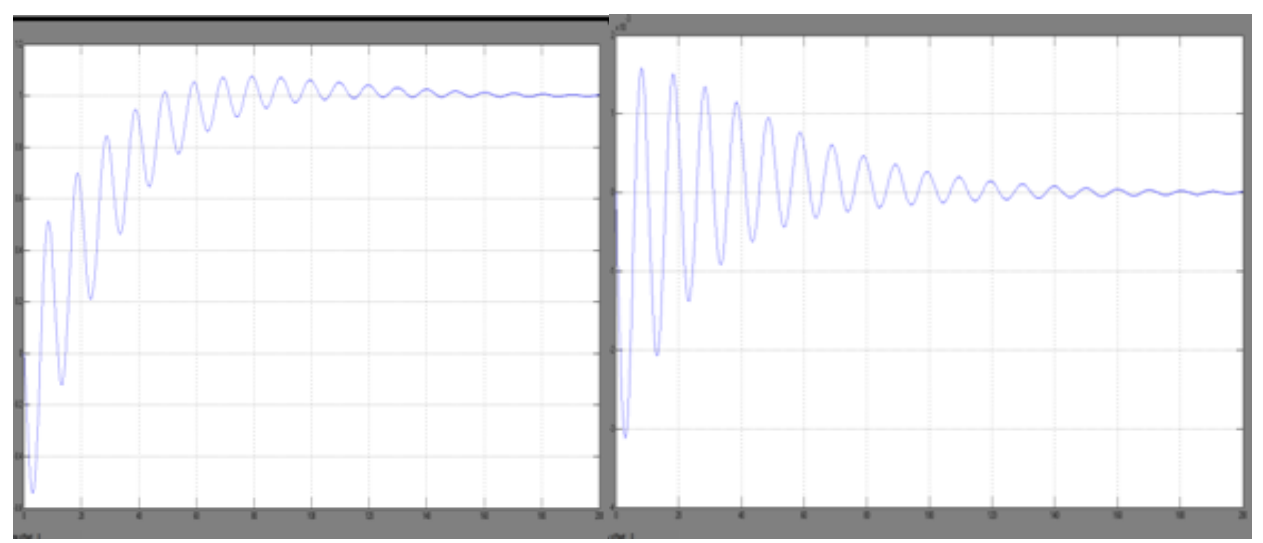

Figure 8. Improved responses of Mc-Avoy controllers for mill torque(left) and buffer chute height (right)

The MIMO systems have severe loop interactions which degrades the set point tracking performance of the control system.In order to avoid loop interactions decoupling of the system is done. To check the possibility of decoupling usually condition number investigation is done by singular value analysis [13]. If the gain matrix of a $2 \times 2$ plant is given as:

$$
[G(s)]=\left[\begin{array}{ll}
g_{11}(s) & g_{12}(s) \\
g_{21}(s) & g_{22}(s)
\end{array}\right]
$$

Then, the interaction compensator matrix for achieving decoupling is given below [16]:

$$
\left[G_{I}(s)\right]=\left[\begin{array}{cc}
1 & g_{I 1}(s) \\
g_{I 2}(s) & 1
\end{array}\right]
$$

Where,

$$
\begin{aligned}
& g_{I 1}(s)=\frac{-g_{12}(s)}{g_{11}(s)} \\
& g_{I 2}(s)=\frac{-g_{21}(s)}{g_{22}(s)}
\end{aligned}
$$

Here $g_{I 1}(s)$ and $g_{I 2}(s)$ are the gains of the interaction compensators for loop 1 and loop 2 respectively. 
Now, the modified simulink model incorporating the two interaction compensators (decouplers) using Equation (12) and (13) is shown in the Figure 9.

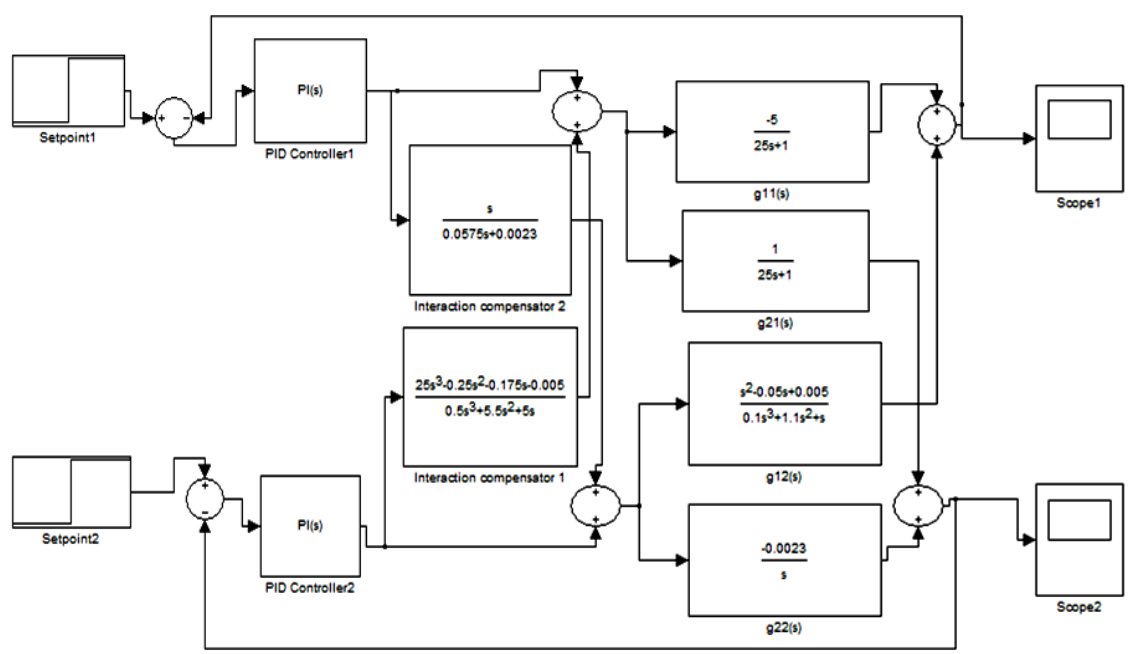

Figure 9. Simulink model of multiloop controller with decouplers

The following relations hold good for the model in Figure 9.

$$
\begin{aligned}
& {\left[\begin{array}{l}
u_{1}(s) \\
u_{2}(s)
\end{array}\right]=\left[G_{I}(s)\right]\left[\begin{array}{l}
v_{1}(s) \\
v_{2}(s)
\end{array}\right]} \\
& {\left[\begin{array}{l}
y_{1}(s) \\
y_{2}(s)
\end{array}\right]=[G(s)]\left[\begin{array}{l}
u_{1}(s) \\
u_{2}(s)
\end{array}\right]}
\end{aligned}
$$

Here $v_{1}(s)$ and $v_{2}(s)$ are the outputs of the two PI controllers of Figure 9.

Combining Equation (14) and (15) we get:

$$
\left[\begin{array}{l}
y_{1}(s) \\
y_{2}(s)
\end{array}\right]=[G(s)]\left[G_{I}(s)\right]\left[\begin{array}{l}
v_{1}(s) \\
v_{2}(s)
\end{array}\right]
$$

Which gives the following results:

$$
\begin{aligned}
& y_{1(s)}=\left[g_{11}(s)-\frac{g_{12}(s) g_{21}(s)}{g_{22}(s)}\right] v_{1}(s) \\
& y_{2(s)}=\left[g_{22}(s)-\frac{g_{12}(s) g_{21}(s)}{g_{11}(s)}\right] v_{2}(s)
\end{aligned}
$$

Thus we get two independent decoupled SISO systems $\mathrm{v}_{1}-\mathrm{y}_{1}$ (decoupled SISO1) and $\mathrm{v}_{2}-\mathrm{y}_{2}$ (decoupled SISO2) with gains $\mathrm{G}_{1}(\mathrm{~s})$ and $\mathrm{G}_{2}(\mathrm{~s})$. The expressions for $\mathrm{G}_{1}(\mathrm{~s})$ and $\mathrm{G}_{2}(\mathrm{~s})$ determined using Equation (17) and (18) are given below:

$$
\begin{aligned}
& G_{1}(s)=\frac{24.97 s^{4}-0.5674 s^{3}-0.4752 s^{2}-0.0165 s}{0.1437 s^{5}+1.593 s^{4}+1.564 s^{3}+0.1175 s^{2}+0.0023 s} \\
& G_{2}(s)=\frac{24.97 s^{4}-0.5674 s^{3}-0.4752 s^{2}-0.0165 s}{12.5 s^{5}+138 s^{4}+130.5 s^{3}+5 s^{2}}
\end{aligned}
$$

The open loop step responses of these two decoupled systems are shown in Figure 10 and Figure 11. 


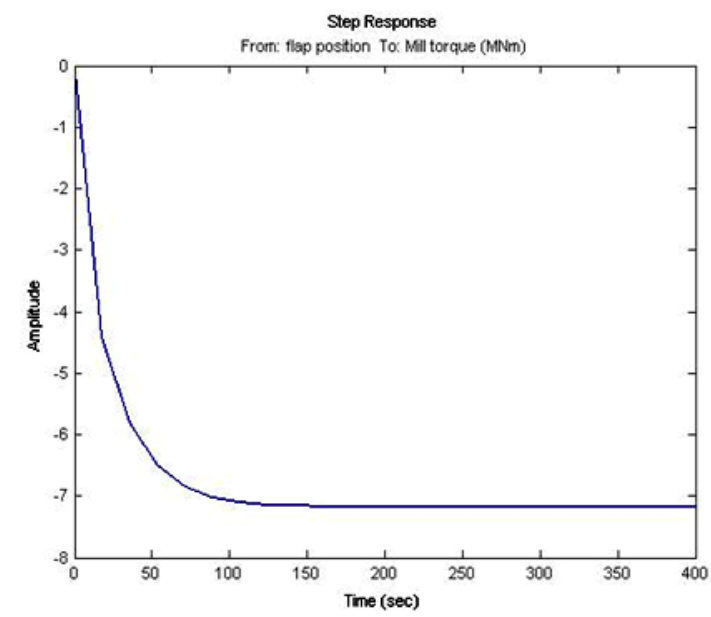

Figure 10. Open loop step response of decoupled SISO 1

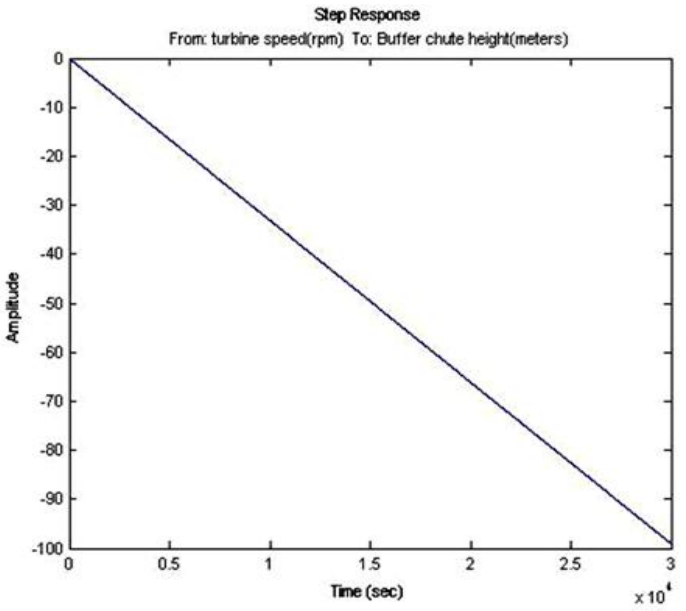

Figure 11. Open loop step response of decoupled SISO 2

The closed loop performance of these decoupled SISO systems with PI controllers with the tuned values specified in Table 4 is shown in Figure 12 and Figure 13 which indicate that the set point tracking performance has got improved as compared to that of composite $2 \times 2$ system (Figure 8 ) as the loop interactions are minimized by decoupling.

Table 4. Parameters of tuned PI controllers for decoupled SISO system

\begin{tabular}{cc}
\hline Parameter & Value \\
\hline $\mathrm{K}_{\mathrm{p} 1}$ & -0.00010 \\
$\mathrm{~K}_{\mathrm{i} 1}$ & -0.0036682 \\
$\mathrm{~K}_{\mathrm{p} 2}$ & -1.4681 \\
$\mathrm{~K}_{\mathrm{i} 2}$ & -0.0049654 \\
\hline
\end{tabular}

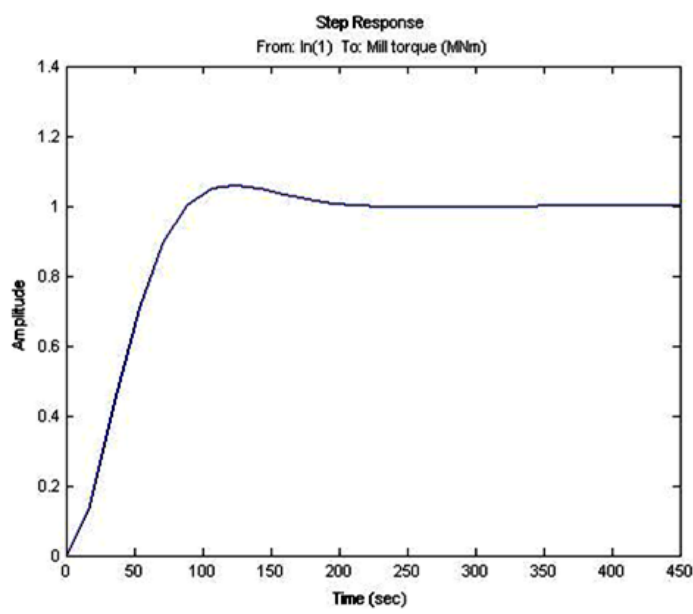

Figure 12. Closed loop step response of decoupled SISO

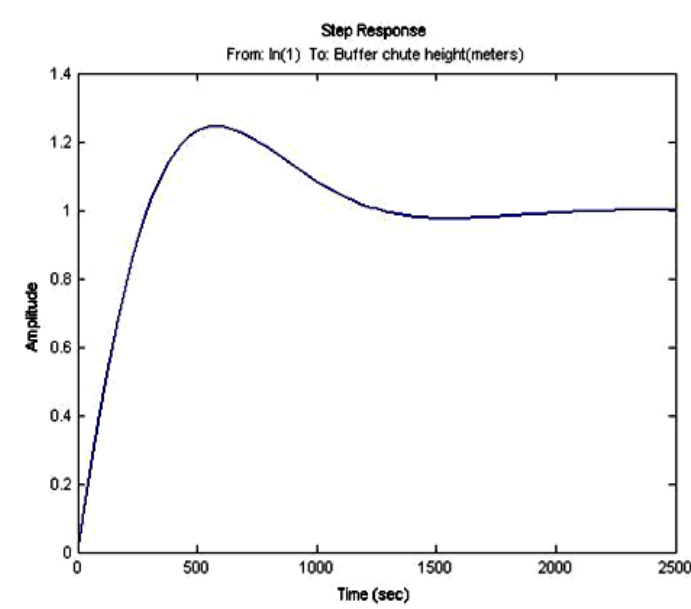

Figure 13. Closed loop step response of decoupled SISO 2

The characterstics of the responses in Figure 12 and Figure 13 are presented in Table 5 and Table 6 respectively. 
Table 5. Closed loop step response characterstics of decoupled SISO 1 system

\begin{tabular}{lc}
\hline Parameter & Value \\
\hline Rise time(sec) & 59.7 \\
Setteling time(sec) & 175 \\
Overshoot (\%) & 5.77 \\
Peak amplitude & 1.06 \\
\hline
\end{tabular}

Table 6. Closed loop step response characterstics of decoupled SISO 2 system

\begin{tabular}{lc}
\hline Parameter & Value \\
\hline Rise time(sec) & 224 \\
Setteling time(sec) & $1.7 \times 10^{3}$ \\
Overshoot $(\%)$ & 24.5 \\
Peak amplitude & 1.25 \\
\hline
\end{tabular}

Now, the setpoint tracking responses of the MPC based control system with sampling interval of 1 second for the same considered model of sugarcane crushing mill is shown in Figure 14 which indicates that this response has a settling time of 28.3 seconds for the mill torque.

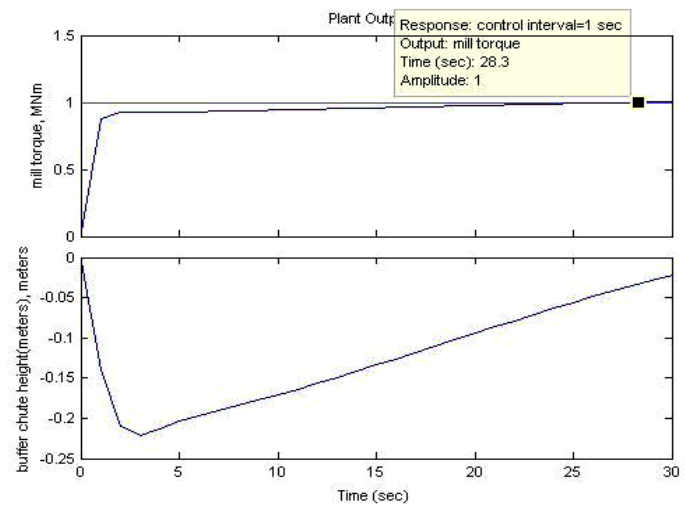

Figure 14. Set point tracking response of MPC

The compative study of Figure 8 and Figure 14 clearly indicates that MPC shows much better performance than conventional PID controllers.

Further the effect of variation of the sampling interval for MPC in the setpoint tracking response is revealed in Figure 15. The responses are obtained for three different values of sampling interval which are 1, 2 and 3 seconds. The setteling times of these responses for the crucial parameter, mill torque are observed to be $28.3,39.7$ and 49.8 seconds respectively which clearly shows the degradation in performance with increase in the value of sampling interval.

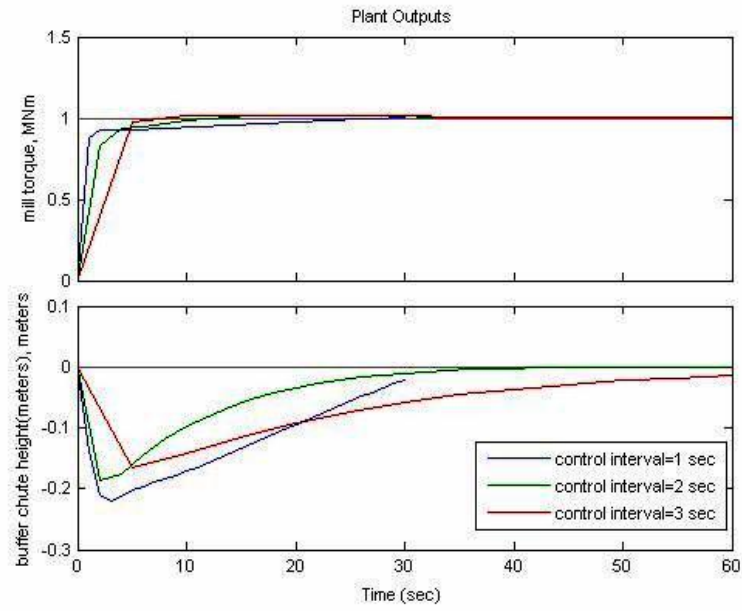

Figure 15. Set point tracking response of MPC for sampling interval of 1, 2 and 3 seconds

Multiloop and Prediction Based Controller Design for Sugarcane Crushing Mill... (Sandeep Kumar Sunori) 


\section{CONCLUSION}

In the present work the multivariable analysis of a sugarcane crushine mill plant has been done by determining RGA which suggested the suitable loop pairing for designing controller. The calculated value of Niederlinski index indicated that this system has good closed loop stability.

The multiloop controller has been designed using Mc Avoy tuning procedure and an acceceptable setpoint tracking performance was observed. After decoupling, the controller performance has been observed to better than the multiloop controller for the composite system.

The performance of prediction based controller is observed to be excellent with a very small setteling time.An increase in the value of sampling interval for MPC has resulted in an increase in the settling time of the response.

\section{REFERENCES}

[1] R. Sivakumar, K. Suresh Manic, V. Nerthiga, R. Akila, K. Balu, "Application of Fuzzy Model Predictive Control in Multivariable Control of Distillation Column", International Journal of Chemical Engineering and Applications, Vol. 1, No. 1, June 2010.

[2] Michał Rogalewicz,Politechnika Poznańska, Piotrowo and Poznań, "The Methodology of Controlling Manufacturing Processes with the Use of Multivariate Statistical Process Control Tools", Journal of Trends in the Development of Machinery and Associated Technology, Vol. 17, No. 1, pp. 89-93, 2013.

[3] Mohammed A. Rahim, Yasir A. Siddiqui and Moustafa Elshafei, "Integration of Multivariate Statistical Process Control and Engineering Process Control", Proceedings of the 2014 International Conference on Industrial Engineering and Operations Management, Bali, Indonesia, 2014.

[4] Taeib Adel, Ltaeif Ali and Chaari Abdelkader, "A PSO Approach for Optimum Design of Multivariable PID Controller for nonlinear systems", International Conference on Control, Engineering \& Information Technology (CEIT'13) Proceedings Engineering \& Technology, Vol. 2, pp. 206-210, 2013.

[5] P. Naidoo, D. T. P. Govender and T. I. van Niekerk, "System Integration of a Multivariable Process Plant Utilising an Intelligent Control Technique", Journal of Achievements in Materials and Manufacturing Engineering, Vol. 31, No. 2, pp. 540-546, 2008.

[6] Daoutidis, Prodromos, Soroush, Masoud, Kravaris and Costas, "Feedforward/Feedback Control of Multivariable Nonlinear Processes", AIChE Journal, Vol. 36, No. 10, pp. 1471-1484, October 1990.

[7] Dan Altena, Michael Howard, Keith Bullin and Joel Cantrell, "Advanced Multivariable Control of a Turboexpander Plant", Proceedings of the Seventy-Seventh GPA Annual Convention, Tulsa, 1998.

[8] A. H. Mazinan, "An Intelligent Multi-multivariable Dynamic Matrix Control Scheme for a 160 MW Drum- type Boiler-Turbine System”, Journal of Electrical Engineering \& Technology, Vol. 7, No. 2, pp. 240-245, 2012.

[9] R. Hanuma Naik, D. V. Ashok Kumar and K. S. R. Anjaneyulu, "Control Configuration Selection and Controller Design for Multivariable Processes Using Normalized Gain", World Academy of Science, Engg., and Technology, International Journal of Electrical, Computer, Electronics and Communication Engineering, Vol. 8, No. 10, 2014.

[10] Xiangrong Shi,Yan L. V., Zhengshun Fei and Jun Liang,"'A Multivariable Statistical Process Monitoring Method Based on Multiscale Analysis and Principal Curves", International Journal of Innovative Computing, Information and Control, Vol. 9, No. 4, pp. 1781-1800, April 2013.

[11] Hamid Behzad, Saeed Khorashadizadeh and Ali Akbarzadeh Kalat, "A Robust Adaptive Method to Control the Crushing Mill Machine”, ICCIA, 2011.

[12] A. Niederlinski, "A Heuristic Approach to Design of Linear Multivariable Interacting Control Systems", Automatica, Vol. 7, pp. 691, 1971.

[13] D. D. Bruns and C. R. Smith, "Singular Value Analysis:A Geometrical Structure for MV Processes", Preprint of the 1982 AIChE Journal, Vol. 25, pp. 1043, 1979.

[14] E. H. Bristol, "On a New Measure of Interactions for Multivariable Process Control", IEEE Transaction, Auto. Cont., Vol. 11, pp. 133, 1996.

[15] T. J. Mc Avoy, "Interaction Analysis Theory and Application", ISA, Research Triangle Park NC, 1983.

[16] Babatunde A. Ogunnaike and W. Harmon Ray, "Process Dynamics, Modeling and Control", Oxford University Press, 1994.

[17] Rekha Rajan, Muhammed Salih P., and N. Anil Kumar, "Speed Controller Design for Steam Turbine", International Journal of Advanced Research in Electrical Electronics and Instrumentation Engineering", Vol. 2, No. 9, 2013.

[18] Junxia Mu and David Rees, "Approximate Model Predictive Control for Gas Turbine Engines", Proceeding of the 2004 American Control Conference, Boston, Massachusetts, 2004. 


\section{BIOGRAPHIES OF AUTHORS}
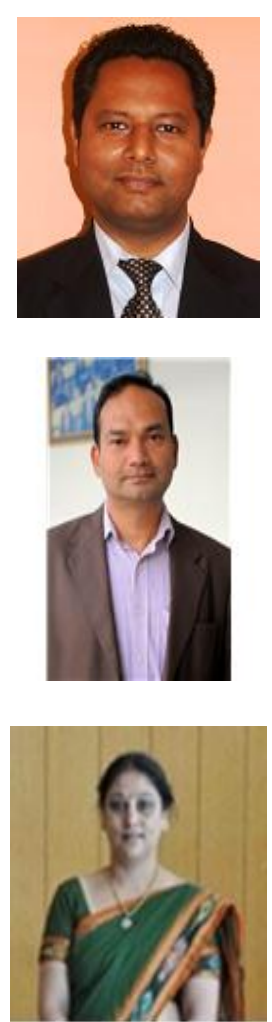

He is working as an Asst. Professor in ECE department of Graphic Era Hill University; Bhimtal Campus.He earned his M.Tech degree in Digital Communication from U.P.T.U, Lucknow and B.Tech degree in Electronics and Communication from Birla Institute of Applied Sciences, Bhimtal. He has an experience of around 12 years of teaching and administration.He is a life time member of ISTE.His areas of interest are multivariable control system, digital design and signal processing.

He has a Ph.D from IIT Roorkee in the area of Control Systems. He earned his M.Tech degree in Instrumentation Engineering from University Campus, DAVV, Indore and B.Tech in Electronics \& Instrumentation from Institute of Engg. And Tech., University Campus, M.J Prohilkhand University, Bareilly. He is presently working as Professor in EEE Department, GEU, Dehradun. He has 15 years of teaching and research experience. He has been the recipient of MHRD scholarship for two years at IIT Roorkee during Ph.D. and New Idea Fund scholarship at CEERI Pilani for one year during M.Tech. He is a life member of ISTE and annual member of IPPTA. His research interests include multivariable control system, prediction based control systems, modern control system, system theory, fuzzy control system and a process control.

She is working as Professor in ECE department of GEU, Dehradun. She has and PhD from IIT Roorkee. She has a vast experience in the area of teaching, research and administration. She has worked as a faculty member for around 15 years and has taught several core courses like Basic Electronics, Electronic Devices and Circuits, Communication Engineering etc as well as advanced courses like Soft Computing Fuzzy Logic Control System, Artificial Intelligence etc. She has been involved in the research area of design of Fuzzy controllers for Industrial Applications. She has to her credit many National and International publications. 